\title{
Filantropía, Educación y Fútbol: La Obra Benéfica de Max Bembo en Barcelona (1907-1922)
}

\author{
Philanthropy, Education and Football: The Charitable Work of \\ Max Bembo in Barcelona (1907-1922)
}

\author{
Xavier Torrebadella-Flix * \\ Universidad Autónoma de Barcelona
}

\begin{abstract}
El siglo pasado ha sido considerado como el de los derechos de la infancia. A principios del siglo XX el desarrollo económico, industrial y cultural de la ciudad de Barcelona conlleva una importantísima transformación urbana cuyos efectos se hacen sentir en una densa concentración de la población obrera que tiene que hacer frente a una multitud de penurias y desigualdades sociales. En este contexto surge un movimiento de beneficencias institucionales que tienen por objetivo la educación y la protección a la infancia desamparada. Entre todas estas iniciativas se destaca la inédita obra benéfica de Max Bembo (José Ruiz Rodríguez), figura en la que centramos el objeto de estudio de esta investigación. Una revisión documental de fuentes primarias de índole hemerográfica y el posterior análisis de los textos seleccionados sustentan una interpretación en torno a la Teoría Crítica. La obra filantrópica de Max Bembo trasciende el concepto benéfico y se incorpora en el campo de la justicia social al utilizar el fútbol como un dispositivo de normalización y de integración ciudadana. Con este artículo nos hemos propuesto superar el espacio residual que tiene aún hoy la Historia de la Educación Social y avanzar en la construcción de una disciplina que sostiene amplias conexiones sociales (políticas, culturales, económicas...).
\end{abstract}

Descriptores: Educación, Deporte, Infancia, Niño desfavorecido, Integración social.

The last century has been considered as the rights of children. At the beginning of the twentieth century the economic, industrial and cultural development of the city of Barcelona entails a very important urban transformation whose effects are felt in a dense concentration of the working population that has to face a multitude of hardships and social inequalities. In this context, there is a movement of institutional beneficences that aim at education and protection of the destitute children. Among all these initiatives is the unpublished charitable work of Max Bembo (José Ruiz Rodríguez), figure in which we focus the object of study of this research. A documentary review of primary sources of hemerographic nature and the subsequent analysis of the selected texts support an interpretation around Critical Theory. Max Bembo's philanthropic work transcends the beneficial concept and is incorporated into the field of social justice by using football as a standardization and citizen integration device. With this article, we have proposed to overcome the residual space that still has the History of Social Education and advance in the construction of a discipline that supports broad social (political, cultural, economic ...) connections.

Keywords: Education, Sport, Childhood, Disadvantage children, Social integration.

*Contacto: xtorreba@gmail.com

ISSN: 2254-3139

www.rinace.net/riejs/

revistas.uam.es/riejs
Recibido: $\quad 17$ de marzo 2017

$1^{\text {a }}$ Evaluación: 31 de mayo 2017

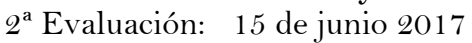

Aceptado: 12 de julio 2017 


\section{Introducción}

El siglo pasado ha sido considerado como el de los derechos de la infancia (Rodríguez Pérez, 2009). A principios del siglo $\mathrm{Xx}$, en las ciudades más urbanizadas e industrializadas del país, las alarmas se dispararon ante el problema social que suponía la explotación de una populosa población infantil obrera expuesta a la agitada y turbulenta vida moderna (Santos, 2012). La desescolarización, la mendicidad, la delincuencia, el alcoholismo y la prostitución azotaban a esta población menor que sucumbía víctima de las desigualdades de clase y de las enturbiadas praxis políticas. En este escenario apareció todo tipo de medidas políticas (higiénicas, educativas, benéficas, culturales y legislativas) encaminadas a resolver el llamado problema social de la infancia desprotegida. Un sistema legislativo y social pro-infancia se puso en marcha para combatir los altos índices de mortalidad infantil, los malos tratos familiares y en el trabajo, la explotación laboral de los menores, la falta de higiene en los hogares o la desescolarización.

En este constructo se hacía sentir la especial virulencia de las insatisfacciones sociales acrecidas por los desequilibrios de la crisis finisecular y el movimiento crítico de corte regeneracionista. La puesta en marcha en 1901 de un nuevo sistema educativo (inspirado en el modelo francés de Julles Ferry) comportó la obligatoriedad de la escolarización. Surgía así una nueva construcción social de la infancia y un conjunto de políticas sociales encaminadas a salvaguardar los valores potenciales (regeneracionismo, idea del "hombre nuevo") de un nuevo estrato social (Ballester y Balaguer, 1995). No obstante, el nuevo sistema también demostró la inoperancia de propósitos socializadores y nacionalizadores hacia la población infantil de la clase obrera.

Por otro lado, aún y las buenas intenciones legislativas en torno a la protección a la infancia, la situación se mostraba perturbadora. La Ley de protección a la infancia y represión de la mendicidad, de 1904, no sirvió para reparar los verdaderos problemas, sino que judicializó y estigmatizó todavía más a la clase obrera, alejándose de toda "igualdad de derechos y de justicia social" (Barona, 2007, p. 297).

En esta coyuntura se entrecruzaba la aparición del deporte del último tercio del s. XIX (y de la educación física), cuyos discursos metaforizados de valores regeneracionistas señalaron el entorno escolar como uno de sus objetivos (Torrebadella, 2014). Así, siguiendo el modelo de la Inglaterra victoriana, el deporte se presentaba como un elemento de reformismo en la enseñanza tradicional, pero también como un elemento socializador de la clase proletaria (Hutchinson, 2008).

En España, Barcelona representó una de las ciudades más paradigmáticas en las que confluyeron estos elementos sociales que acabamos de describir. Entre las numerosas iniciativas institucionales (públicas y privadas) pro infancia rescatamos del olvido la genuina obra, y prácticamente desconocida, de José Ruiz Rodríguez, más conocido por Max Bembo. Sobre este personaje descansa el objetivo de este estudio, que no es otro que el de revelar la contribución filantrópica y benéfica de la llamada fundación Obra de Max Bembo. A través del análisis de esta fundación de Bembo comprobamos una institucionalización social de medios de protección y educación de la infancia desamparada en la Barcelona de principios del siglo Xx. Entre todos estos medios nos centramos en el fútbol, un deporte entonces nuevo, sobre el cual se promovieron valores 
y modos de gubernamentalidad, construidos desde la misma sociedad para proyectar los dispositivos disciplinarios deseados por la clase dominante.

Sobre Max Bembo apenas existen estudios (Alsina, 1982; Masjuan, 2006). Es por esto que los pocos datos biográficos que presentamos han sido hilvanados a través del cruce de múltiples textos y noticias de prensa. Por consiguiente, una primera parte de la metodología ha consistido en localizar fuentes hemerográficas de la prensa histórica y obras bibliográficas que se ocupan parcialmente del asunto. Tras el posterior análisis y ordenación de los datos, hemos elaborado un breve apunte contextual que triangula en torno al conflicto social que se desprende del desarrollo industrial, urbanístico y económico de Barcelona. La revisión de obras generales en torno a la historia de la educación social ha permitido la contextualización y las bases para el discurso crítico (Ferrer, Somoza y Badanelli, 2014; Ruiz y Palacio, 1999; Vilanou y Planella, 2010). Por lo tanto, el problema asistencial y pedagógico de la infancia, junto a la emergencia social del deporte, emplazan la obra de beneficencia de Max Bembo, a una visión pedagógica y cuya relación con el deporte, en especial el fútbol, proporciona los argumentos clave para un análisis teorético en torno a la sociología crítica y la sociología del poder. Al respecto, disponemos de un corpus de textos lo suficientemente significativo para bosquejar en la intertextualidad del discurso dado. Manejamos pues la autoridad sugestiva del texto de la época "como fenómeno social complejo, lugar de registros inconscientes donde se inscriben usos, gestos, códigos, en fin, relaciones objetivas de las que no son conscientes sus autores" (Vázquez García, 1989, p. 91). En sí, como trata Le Goff (1991), utilizamos los textos con la intención de recuperar la memoria del monumento/documento (1991), y considerar como "expresan el poder de la sociedad del pasado sobre la memoria del futuro" (Le Goff, 2012 p. 11).

\section{La clase obrera, educación y deporte en la Barcelona de principios de siglo $\mathrm{XX}$}

Afectada por el Desastre del 1898, la Barcelona de principios del siglo XX soportaba los desequilibrios sociales y las contradicciones del emergente crecimiento urbanístico y económico. La política de la ciudad entraba en disputas territoriales y económicas de la clase burguesa, y en las clases populares afloraba un sentimiento de catalanismo ante una España intransigente. La sociedad barcelonesa (la catalana en general) se mostraba enemistada con las decisiones políticas de Madrid y se manifestaban las demandas y aspiraciones de un autogobierno regionalista. En Cataluña, los conflictos generados a raíz de las guerras de Cuba y de Marruecos agudizaron el sentimiento antimilitarista de la población, especialmente en la clase obrera, pero también con la clase dirigente y empresarial, que aprovechaban su condición para confluir y protestar por sus intereses económicos. En este conflicto, las desigualdades sociales se hacían sentir profundamente en la población infantil y los proyectos de escolarización aparecían justificados por el creciente desgobierno social; situación de caos, cuyas críticas políticas responsabilizaban (irracionalmente) a la degeneración de clases obreras.

En estos años, aún y la ley de escolarización obligatoria hasta los doce años, los índices de niños y niñas sin escuela eran preocupantes y una significativa población era forzada al trabajo (explotación infantil). Los que no trabajaban ni asistían a la escuela vagaban o jugaban entre las calles del centro de Barcelona, la mayoría destinados a la mendicidad, 
al pillaje y a otras situaciones poco saludables. Esta realidad era aborrecida por la consolidada burguesía que deseaba pasear por unas calles limpias de indigencia y miseria (suciedad). En este contexto nació una conciencia colectiva burguesa y el impulso de instituciones privadas de atención a la infancia y a su educación. Estas iniciativas venían a cubrir el déficit de asistencia social y educativa de las instituciones públicas. Del patrocinio de estas instituciones se construyó el discurso filantrópico (y religioso) de una sociedad dispuesta a salva-guardar la infancia de la exclusión social. Discursos que, en definitiva, tenían el objetivo de redirigir la infancia en peligro hacia una dignificación y moralización para incorporarla a la sociedad productiva. Se construía así, el mito de la infancia peligrosa; el de una población que representaba una amenaza para el status quo de una ciudad cosmopolita, moderna y civilizada que deseaba confraternizar con Europa (Torrebadella, 2017; Torrebadella y Brasó, 2017).

Ante los miedos de la degeneración se concibieron las tecnologías políticas de una medicina social, situando un especial cerco en la atención de la población infantil de la clase obrera (Ballester y Balaguer, 1995; Campos, 1998). Entre estas medidas se encontraba la escolarización obligatoria, cuya intención era "apartar al niño proletario de la calle y modelar su conciencia para garantizar la paz social y la reproducción de la mano de obra" (Campos, 1998, p. 346). Por supuesto, entre las tecnologías de control social también se hallaban la gimnástica y el deporte escolar. Y, por consiguiente, en la educación física se alojaron los dispositivos disciplinarios (códigos higiénicos y moralizadores, además de la conductibilidad de valores liberales asumidos por la docilidad y la obediencia: esfuerzo, resistencia, valor, superación, lucha...) que eran compartidos en el imaginario colectivo a partir de la naturalización modernizadora que se alojaba en el mito regeneracionista (Torrebadella, 2017; Torrebadella y Brasó, 2017).

En la Barcelona de principios del siglo Xx, las preocupaciones sociales movilizaban un apego especial a la protección de la infancia (Sánchez-Valverde, 2009; Santolaria, 2009). En 1907, la ciudad concentraba 37 instituciones de beneficencia a la infancia (Ayuntamiento de Barcelona, 1909). La atención al llamado problema social, es decir, al control sobre la clase obrera, tenía en jaque a la clase dominante, que visionaba el elemento obrero como una amenaza a sus intereses económicos. Por lo tanto, las clases dirigentes estaban moralmente condicionadas a sufragar, con la ayuda de la Iglesia, la beneficencia de la indigencia. Así, al llegar a 1912, la asistencia pública de la ciudad había crecido considerablemente, y disponía de 72 instituciones, entre éstas, numerosos asilos de huérfanos o desamparados, perteneciendo, la mayoría, a las fundaciones o congregaciones religiosas (Ayuntamiento de Barcelona, 1914).

La estigmatizada percepción de concebir a la clase obrera como lacra de degeneración, portadora de gérmenes patógenos, de vicios morales, de la agresividad y criminalidad, etc. (Juderías, 1908), fue asumida en un discurso de las clases pudientes que se responsabilizaron de ejercer su autoridad en las políticas sociales. Médicos, higienistas, pedagogos, militares o eclesiásticos se disputaron los dominios de acción sobre el problema de la clase obrera, y todos tenían ideas para proteger a la sociedad. Desde estos estamentos se proyectaron discursos que convergieron hacia la construcción de una representación social (imaginario colectivo) de una infancia obrera estigmatizada como sucia, decadente y peligrosa. De este constructo aparecieron iniciativas de escolarización (reclusión-instructiva) para sociabilizar la clase obrera, pero también para proteger a la buena ciudadanía de las amenazas degeneracionistas o revolucionarias. La escuela primaria pública se convertía pues, en un espacio represor y regenerador de la infancia 
obrera; es decir, en un encarcelamiento cuyo objetivo pasaba por domesticar, civilizar, sociabilizar y, así, prevenir la "degeneración de la raza” (Álvarez-Uría, 1987; Barona, 2007; Carreño, 2009; Del Cura y Huertas, 2009; Huertas, 1998, 2004, 2009; Varela, 1991). Entonces, surgía la mano benefactora del Estado que concibió la escolarización como una de las soluciones más importantes para establecer el orden público y garantizar la seguridad general; y era precisamente esta educación la garantista de la "paz civil", es decir, la que construía el disciplinado y dócil obrero o el sacrificado soldado del mañana (Solana, 1909).

En estos procesos de escolarización, de renovaciones pedagógicas de los métodos de la enseñanza tradicional, de preocupación por la educación física y el regeneracionismo, coincidieron en la coyuntura de expansión del deporte, que brotaba paralelamente al desarrollo industrial y el crecimiento urbanístico de las ciudades. Los desajustes sociales conformaron un espacio de tensiones nacionales y los conflictos políticos y laborales representaron el constante latir de las ciudades. En Barcelona, los episodios de la Semana Trágica, los atentados políticos, las huelgas generales de 1917 y 1919, y las revueltas militares, sirvieron para remover la conciencia social y la multiplicación de iniciativas apaciguadoras de conflictos.

En estos años se iniciaba una renovación de la enseñanza tradicional. Las proyecciones de ensayos escolares en el marco de la Escuela Nueva situaban a Barcelona en el principal centro de atención europeo. La Escuela Moderna de Francisco Ferrer Guardia, la obra reformista del Ayuntamiento de Barcelona y otras iniciativas privadas vinculadas a la burguesía representaban una declarativa voluntad de cambiar los modos tradicionales de enseñanza (González-Agàpito, 1992). Las nuevas escuelas encarnaban singulares ensayos, en donde la educación física y el deporte tenían un especial protagonismo. Es un ejemplo paradigmático la Escola de Mestres, en la que el polifacético pedagogo Joan Bardina fomentó la gimnasia sueca y deportes como el fútbol (Torrebadella, 2013). Sin embargo, contrastaba el déficit de escuelas públicas, el mal estado de las mismas y la carencia de todo tipo de medios para la enseñanza (Cañellas y Toran, 1982). En estas escuelas ni tan siquiera se hacía educación física y, en unas pocas, solamente se hacía "gimnasia higiénica" o "gimnasia respiratoria" (Torrebadella, 2013; Torrebadella y Brasó, 2017).

Las escuelas que asistían a la clase obrera, aunque con diferenciaciones ideológicas substanciales, les unía un objetivo en común. La red de escuelas vinculadas a la Escuela Moderna de Francisco Ferrer Guardia, las escuelas catalanas del Distrito II y VI, las escuelas del Patronato de la Sagrada Familia del padre Gil Pares o las escuelas de ensayo del Ayuntamiento de Barcelona (escuela del Bosc y escuela del Mar), atendían a la filantrópica obra asistencial de una temerosa sociedad liberal que se esforzaba en reciclar los detritos anti-sociales que ella misma generaba (Torrebadella, 2016).

El deporte de Barcelona se enmarcaba en un contexto urbano de prosperidad (un proceso de europeización y de conciliación social interno de la ciudad) que también era estimulado por actores políticos, destacándose la Lliga Regionalista de Prat de la Riba y la administración de la Mancomunitat (Pujadas y Santacana, 1995). En esta coyuntura hay que añadir la presencia de significativos promotores del deporte (o regeneración física) que, bajo el sello regeneracionista, también aspiraban a una ciudad modélica (Torrebadella, 2015a). En este ideal, brotaba del protagonismo de los gimnasios de Barcelona, los cuales encabezaron las iniciativas del deporte y fueron los verdaderos 
generadores del asociacionismo deportivo. Paralelamente, los colegios más elitistas de la ciudad también seguían la moda del sport inglés, que se visualizaba como etiqueta de distinción y de regeneración física y moral (de regeneración socializadora de la juventud). Por su parte, los profesores de educación física demandaban campos y plazas de juego para la población infantil (Torrebadella, 2015b); con ello también se buscaba el no molestar a los transeúntes y el presentar la imagen de una ciudad moderna, cultural, europea y civilizada. La cultura física (la gimnástica y el deporte) se envolvía de un discurso de índole regeneracionista y catalanista (Torrebadella, 2014) que se extendía hacia las clases populares con el apoyo de entidades como el Centre Autonomista de Depedents del Comerç $i$ de la Indústria (CADCI) y el Ateneo Enciclopédico Popular. Barcelona se convertía en un importante núcleo promotor del deporte nacional, pero también en el principal foco de las desigualdades sociales. En este escenario, el fútbol encarnaba el motor del creciente asociacionismo deportivo y se autoproclamaba como el instrumento re-formador de la juventud (Torrebadella, 2012b, Torrebadella y Nomdedeu, 2015).

\section{La obra benéfica de Max Bembo}

Max Bembo (José Ruiz Rodríguez) era hijo de Diego Ruiz de los Cobos, médico malagueño, y de la granadina Carmen Rodríguez Méndez. Su hermano era el polifacético Diego Ruiz Rodríguez (1881-1959: poeta, médico, filosofo, librepensador seguidor de Nietzsche, miembro de la Asociación Internacional de Trabajadores y autor de polémicas obras como El Crim dels Reis Catòlics i la fi de Castella, 1932). José y Diego eran primos hermanos de Pablo Ruiz Picasso (Alsina, 1982). A finales del siglo XIX ambos hermanos se instalaron en Barcelona, bajo la protección de su tío materno, el distinguido catedrático de Higiene Privada Rafael Rodríguez Méndez (Granada, 1845-Barcelona, 1919; médico, político del Partido Republicano Radical, Rector de la Universidad de la Universidad de Barcelona entre 1902 y 1905, Presidente de la Federación Gimnástica Española entre 1898 y 1906), y masón de la Logia Constancia de Gracia). Rafael Rodríguez Méndez tuvo dos hijos con Catalina Trinidad Ruiz de los Cobos: Ángel Rodríguez Ruiz y Rafael Rodríguez Ruiz. Ángel Rodríguez Ruiz fundó en 1900 la Sociedad Española de Foot-ball y Rafael Rodríguez Ruiz, doctor en medicina, estuvo muy vinculado a la Federación Gimnástica Española.

A principios del siglo Xx, aparece en la escena barcelonesa Maximiliano Bembo (Max Bembo), escritor y maestro de clase media, que se daba a conocer en La Vanguardia con artículos de crítica social y moral. A primeros de enero de 1907, Bembo declaraba sus intenciones:

Una persona de buena voluntad, Max Bembo, escritor poco conocido, deseando aliviar la suerte de los que, en virtud de una ley de nuestra alcaldía, van á ser recogidos, ha proyectado fundar una «Escuela de desamparados para la educación de los pobrecitos de la ciudad», dándoles mesa, cama, libros, cariño y tranquilidad.

Se dirige á los hombres influyentes qua con sus talentos honran la ciudad, á los generosos aristócratas, á nuestros gobernador y alcalde, á nuestros concejales y diputados y á nuestros periodistas, para que vean con los ojos que él lo ve, su proyecto, le concedan el apoyo material y espiritual que de todos necesita, crean en su necesidad, urgencia y oportunidad, y no dejen que se deshaga y caiga de sus manos sin que aproveche a nadie. Su ideal es hacer de los pobrecitos, niños buenos y felices, vivir con ellos el mayor tiempo posible. Establece en su Escuela dos secciones: la 
primera (Filantropía), donde se admitirán los niños desde su más tierna edad y saldrán a los 12 ó 14 años. Su método lo funda:

$1^{\circ}$, no hay más libro que la Naturaleza para el niño; $2^{\circ}$, despertar en el niño el gusto y amor a ser enseñado; $3^{\circ}$, hacerle olvidar sus penas.

La segunda sección (Campos de trabajo) continúa la labor del Filantropía, instalándose, si es posible, en la montaña, y hará del niño pobre un buen agricultor, un buen artista, un buen obrero. La modesta posición de Max Bembo, individuo de la clase media, que es maestro y no le contenta la actual vida, le hace imposible relacionarse con los hombres influyentes, pero suplica a todos que no le olviden y le ayuden a la reforma moral de los desamparados. (Notas locales, 1907, p. 2)

El 27 de enero 1907 Bembo y su hermano Diego Ruiz presentaron en el Ateneo Barcelonés el proyecto de una escuela para niños pobres. Varias convocatorias anunciadas en la prensa y la difusión del folleto "Miseria y filantropía a favor de los desamparados" sirvieron para lograr una mayor adhesión popular a la obra fundacional que nacía de este proyecto (Bembo, 1907a, 1907b, 1907c). Bembo se comprometía en asistir a la miseria de las clases humildes y, con este propósito, ofreció conferencias sobre los niños desamparados en el Ateneo Barcelonés y en el Ateneo Enciclopédico Popular. El proyecto recibió el apoyo de una importante parte de la burguesía, además del Ayuntamiento de Barcelona (entonces presidido por el conservador Domènec Joan Sanllehy Alrichy, de septiembre de 1906 a mayo de 1908), la Diputación Provincial, la Asociación Protectora de la Enseñanza Catalana, Círculo del Liceo y el Centro Nacionalista Republicano, la Liga Regionalista y otras ilustres corporaciones y particulares. Bembo se movía en los círculos de la Unión Catalanista, entonces presidida por el doctor Martí (1984), una de las personas que más se preocupó por los problemas sociales de la clase obrera.

Así se creó el 20 de abril de 1907 la Obra de Max Bembo (OMB), nombre por el que se conocía la institución, cuyo objetivo era el de iniciar una reforma moralizadora de los pobres de la ciudad. De aquí surgió la primera Escuela de Desamparados, finalmente establecida hacia el mes de mayo, en el Torrente de las Flores, 172, en la barriada de la Salud, pero en noviembre fue trasladada a la calle San Salvador, 13 (Barriada de Gracia). Parece que Bembo atravesó algunas dificultades iniciales en cuanto a su credibilidad, situación que provocó, que en Julio 1907, se trasladase a Sabadell con intención de movilizar otro proyecto parecido. Allí organizó en su casa, en la barriada de la Salud, una escuela para los pobres, pero que también abandonó a mediados de diciembre (Alsina, 1982; Masjuan, 2006). No obstante, como trataremos, Bembo regresó a Sabadell a primeros de 1913 .

Otra vez en Barcelona, Bembo continuó con sus proyectos educativos. Conocemos que en 1907, la OMB dependía de la Pía Sociedad Salesiana Don Bosco, haciéndose cargo doce religiosos, que se ocupaban de educar a los hijos de la clase obrera (Ayuntamiento de Barcelona, 1909, p. 409). Esta relación con los salesianos cesó hacia 1911, momento en el que Bembo se independizó.

En enero de 1908 apareció "Paracleto", la primera publicación mensual de la OMB a favor de los desamparados, que se repartía gratuitamente en los hospitales, prisiones, manicomios y casas de caridad. De esta publicación solamente se salieron tres números (Bembo, 1916c; Givanel, 1931). En septiembre de 1908, Bembo se trasladó a la "Masía La Ninfa” (Palau, 1935, p. 207), en la falda de la montaña de Montjuïc, 18 (barriada de 
Hostafrancs), reuniendo una "institución al aire libre" que asistía a 60 niños y 40 niñas donde aprendían tareas de ebanistería, agrícolas, zapatería, imprenta, sastrería...

Bembo estudió muy bien los bajos fondos de Barcelona y fue el autor de "La mala vida en Barcelona "(1912), en donde declaraba su obsesión por eliminar, tanto como fuese posible, el vicio y la corrupción de la ciudad. Presentó con detalle el ambiente de depravación social de Barcelona: el alcoholismo, la prostitución, el juego, la inversión sexual, la corrupción de menores, las condiciones insalubres de la vida familiar, las del trabajo, las supersticiones y las creencias de brujería. Bembo (1912c) escribió esta obra para que la ciudadanía entera entendiese "las bases antropológicas que sostienen el edificio de la pedagogía criminal” (p. 5). Es decir, Bembo analizaba estas cuestiones para educar mejor y proceder a la reforma de la delincuencia: "La población mala de una ciudad es una fuente para el pedagogo y el criminólogo” (p. 5).

La acción de Bembo estaba centrada en atender a la infancia desamparada de los barrios más pobres, es decir, recogía a la infancia vagabunda y anormal con el objeto de alejarla de las conductas desviadas y criminales. Por esto mantuvo todo tipo relaciones con las entidades culturales y promovió que sus alumnos también participasen. Algunos de éstos ingresaron en el Orfeó Graciench y en la Escola de Mestres de Bardina. Bembo era un activista social muy inquieto y no paraba de impartir conferencias y de predicar a beneficio de la infancia obrera. En pocos años se ganó la credibilidad de importantes familias de la burguesía, que colaboran destinando fondos a la OMB, que gestionaba escuelas, talleres, cantinas, pensionados, orfeones, grupos dramáticos, bibliotecas y una escuela sanitaria. Destacar aquí los patronos más importantes que se comprometieron con Bembo: Eusebio Bertrand Serra, Benigno de la Riva, Juan Borés, José Olano y Rodríguez Méndez, además de la colaboración de políticos tan influyentes como Enric Prat de la Riba, presidente de la Diputación de Barcelona.

Entre las muchas iniciativas que emprendió Bembo, una de las más populares fue la celebración anual de los Reyes Magos, ofreciendo a los niños pobres de la fundación todo tipo de obsequios (juguetes, libros, ropa, pelotas, etc.), que donaban benéficamente los comerciantes de la ciudad (De la Riva, 1916).

En septiembre de 1911, Bembo solicitó una subvención al Ayuntamiento para mantener una escuela al aire libre (La Vanguardia, 6 de septiembre de 1911, p. 2). Esta escuela estuvo ubicada en el Hipódromo de Can Túnez y atendía a los hijos de las familias gitanas. En dicha escuela, parece que Bembo idealizó la obra escolar al aire libre que el padre Andrés Manjón organizó en Granada, aunque también seguía una orientación naturista (próxima a la cultura libertaria). En esta escuela el alumnado utilizaba un trozo de playa para bañarse y hacer ejercicios y juegos gimnásticos y, además, contó con la colaboración de la Liga Vegetariana de Cataluña (La Vanguardia, 8 de marzo de 1912, p. 3). En esta época, en el Ayuntamiento se estaban debatiendo las escuelas al aire libre y la necesidad que la ciudad albergase una escuela en el parque de la montaña de Montjuïc (Esteruelas, García, Vilafranca, 2015; La escuela del bosque, 1911). Así podemos citar que Bembo se adelantó a la iniciativa municipal y, por cuenta privada, ya plateó las primeras escuelas al aire libre de Barcelona.

En enero de 1913 Bembo regresó a Sabadell para ocupar el cargo de director en la nueva escuela de la Institución Integral Armónica. Allí inició una intensa campaña de propaganda y conferencias pedagógicas, pero al cabo de unos pocos meses fue reemplazado en el cargo. Se conoce que en Sabadell no fue bien recibido, fue acusado de 
francmasón y despertó los recelos de la burguesía católica (Alsina, 1982; Masjuan, 2006). Bembo regresó a Barcelona, con lo que intensificó, todavía más, la obra iniciada en esta ciudad.

En 1914 también patrocinó una "Obra al aire libre" en la que participaban 16 escuelas con un total de 2.000 niños del Distrito VII (La Vanguardia, 13 de julio de 1915, p. 3), en la montaña Montjuïc (Bembo, 1916c). La movilización de la OMB gozó de un importante reconocimiento social que dio lugar a la creación del "Grupo propagador de las doctrinas de Max Bembo” (La Vanguardia, 24 de agosto de 1915, p. 3).

En 1916, la OMB agrupaba a 300 niños de ambos sexos en varias fundaciones escolares. La $1^{\mathrm{a}}$ Fundación comprendía los Grupos Eusebio Bertrand, escuelas maternales en Hostafrancs (26 de enero, 37, torre), que atendían a la alfabetización de niños y niñas (de 3 a 12 años), por separado, de las familias gitanas. La $2^{\text {a }}$ Fundación eran los Grupos Borés, en el Barrio de la Marina en Casa Antúnez (término de Hospitalet de Llobregat). La $3^{\circ}$ Fundación se encontraba en el Barrio del Arsenal, Casa Antúnez), prestando escolarización a centenares de niños (Bembo, 1916c).

Otra fundación fue la del teatro para niños Taya, iniciada el 15 de marzo de 1914 en el Teatro de Bellas Artes. En este programa participaban 6.000 escolares de las escuelas nacionales, principalmente del Distrito VII, y de otras instituciones de beneficencia infantil. Además, existía la fundación del "Cine para niños" Foronda, que invitaba a estos mismos escolares a presenciar películas, todos los jueves no festivos por la tarde (Bembo, 1916c).

En esta época, Bembo disponía de un consultorio pedagógico (c/ Mendizábal, 30). Puede decirse que ejerció de incipiente psicopedagogo en la infancia, puesto que así se anunciaba al considerarse especialista para tratar a los "niños y jóvenes de ambos sexos mentalmente anormales, retardados, rebeldes a los padres, depravados, perversiones del instinto sexual, invertidos, cleptómanos, alcohólicos y cuántas anomalías afectan a la infancia"

La publicación mensual "La Ciudad de los Niños", portavoz de la OMB, se ocupaba de remover las conciencias y hacía llamadas a la solidaridad ${ }^{2}$. Bembo (1916a, p. 12) exclamaba: “i 50.000 niños en Barcelona, se están muriendo de hambre!!”. Por esto invitaba a las clases pudientes a participar en rutas interpretadas por las zonas más míseras de la ciudad con el objetivo de sensibilizar sobre de las problemáticas sociales de los niños gitanos, los niños llamados escombraires, los niños de la playa de Somorrostro o los del Barrio de la Marina de Casa Antúnez.

Bembo (1912a) también se solidarizó con la prostitución y reunió a los hijos desamparados de las mujeres corrompidas por la "mala vida". En Barcelona, la prostitución infantil también se visionaba como una lacra. Así denunciaba repetidamente las casas secretas de trata de blancas y la corrupción infantil: "Si el pueblo llegara a conocer todos los casos de corrupción de menores quedaría horrorizado" (p. 212). Además, añadía información de quienes eran los que más abusaban de este delito: "Es asombrosa la cifra alta que corresponde a maestros, especialmente eclesiásticos, y de los

\footnotetext{
${ }^{1}$ En "La Ciudad de los niños": publicación mensual, portavoz de la Obra de Max-Bembo, que dará a conocer propósitos y realidades para que sirvan de estímulo a cuantos luchan por la educación moral de la infancia y de consuelo a los que aspiran a una mejor vida, 1916, núm. 3 (contraportada).
} 
que no escapan los mismos titulados laicos, cuyos vandálicos hechos han conmovido siempre a la opinión” (pp. 213-214). En este asunto, Bembo (1916b) fue notoriamente insistente y directo: "Afirmamos que existen también casas públicas de corrupción de menores. Además, podemos asegurar que, hoy día, el menor y la menor son solicitadísimos, y que las conquistas se llevan a cabo, descaradamente" (p. 2). Por lo tanto, Bembo se entregaba por completo a proteger y dignificar la infancia de los "niños mártires", cuya vida estaba condenada a padecer la violencia y la disciplina de los malos tratos, ya sea "en la casa, en la escuela y en el taller" (Bembo, 1912b, p. 134).

Durante los años veinte, la OMB ya era muy popular y ensanchaba los proyectos con otros centros culturales de canto, baile y música, en el que participan reputados profesores especialistas. Bembo fue un enamorado del arte y de la estética y también deseaba trasladar este amor a la clase obrera:

Han quedado definitivamente constituidas las diferentes secciones que han de
integrar el Orfeonato Max Bembo, sito en la calle de San Simplicio, 6. Las clases
serán de gimnasia rítmica, declamación y recitación, solfeo, piano, violín, y
conferencias culturales. El cuadro de profesores lo integran los señores Normand
Solé, director del Orfeón; señora Marti Brainso, señorita Mercedes Vila, don
Aurelio Capmany y don Isidro Grau. Las clases serán gratuitas, habiéndose creado
una clase especial los domingos por la mañana y días festivos, para que los alumnos
y alumnas de las escuelas nacionales y particulares de Barcelona puedan concurrir a
ellas, con el fin de que extiendan su educación escolar con la música y la recitación.
Las horas de matrícula son los lunes, miércoles y viernes, de nueve a doce de la
noche, y los días festivos por la mañana. (Orfeonato Max Bembo, 1920, p. 5)

En la Festividad de Reyes de 1923, Bembo continuaba su filantrópica obra de beneficencia repartiendo juguetes a la infancia. Sin embargo, puede que ésta fuese la última actuación:

La Obra de Max-Bembo ha efectuado el reparto de los lotes y presentes a los cinco
primeros grupos de la Infancia Max-Bembo, acto que tuvo lugar en el casino de la
Barceloneta, cuyo local fue ofrecido desinteresadamente, transcurriendo la fiesta en
medio de la mayor alegría y del mayor orden. Por la mañana del día 6 todas las
niñas y niños enfermos del hospital de la Santa Cruz fueron obsequiados con
juguetes siendo recibidos los comisionados Max-Bembo por la junta del hospital y el
cuerpo facultativo. Por la tarde, la Obra de Max-Bembo llevó, al Hospital Clínico
juguetes para los 55 niñas y niños de la sala de cirugía del doctor Martínez Vargas,
sembrando la alegría en los pobrecitos enfermos. (La Obra de Max Bembo, 1923,
p. 5)

Al llegar a 1923 perdemos el rastro de Bembo y de toda su obra, probablemente por un rechazo oficial y obligado a su institución. Bembo confraternizaba con círculos anarquistas y, suponemos que abandonó el país por causas políticas, ausentándose durante la Dictadura de Primo de Rivera.

La presencia de José Ruiz Rodríguez (Bembo) vuelve a surgir en 1931, con la proclamación de la II República. No obstante, entonces utilizaba el pseudónimo de José Antonio Emmanuel y era conocido entre los sectores anarcosindicalistas declarándose seguidor de Francisco Ferrer Guardia (Ruano, 2013). Colaboró con el Comité Internacional de Escuelas (CIE), con el objeto de fomentar y propagar las escuelas racionalistas o anarquistas (Emmanuel, 1931f), con lo cual, también emprendió la Biblioteca Anarquista Internacional (BAI), en la que publicó varias obras de propaganda ideológica (Emmanuel, 1931 a, b, c, d, e). 


\subsection{El "nuevo Pestalozzi"}

La formación pedagógica de Bembo se destaca al comprobar que, según él, era miembro de la Sociedad de Pedagogía de Génova, de la Société Libre par l'étude psychologuique de l'enfant de Paris (liderada por Alfret Binet y Theodoro Simon) y de la Societé Belge de Pédotechnic. De todos modos, Bembo era un declarado filántropo y se identificaba como un "nuevo Pestalozzi" que, a la sazón, recogía de este influyente pedagogo suizo, el ideal educativo para su obra benéfica.

A mediados de 1909 Bembo dio a conocer la intención de constituir una Agrupación Pestalozzina. El objetivo era el de contribuir a la formación cultural de los maestros y hacerlos seguidores de la obra de Pestalozzi y convertir sus escuelas en una continuación de la de Yverdon. Con este propósito, también proyectó constituir una biblioteca sobre Pestalozzi, propagar su obra y establecer una red internacional de colaboradores simpatizantes con el proyecto (Bembo, 1909). Fue al cabo de un año cuando quedó definitivamente constituida la Agrupación Pestalozzina, cuyo local se encontraba en la calle de las Cortes, 18 (Hostafrancs- Institución Max Bembo) (Bembo, 1910).

Asimismo, Bembo era un ferviente enamorado de la obra del valenciano Francisco Amorós (1770-1848), reconocido como el fundador de la educación física en Francia y en España. Amorós fue uno de los promotores y director del Real Instituto Militar Pestalozziano de Madrid (1806-1808), y se destacó por llevar a cabo un programa de educación física y moral, que heredó de la influencia de Pestalozzi; por eso Bembo elogiaba la labor de ambos (Agrupación Pestalozziana, 1913; Bembo, 1912a, 1912b).

Hacia 1913 Bembo publicó "Doctrina Pestalozziana. Introducción a una historia de la doctrina pestalozziana y los orígenes del conocimiento científico en pedagogía”; una obra que fue dedicada a "Andrés Manjón en quien revive hoy el espíritu de pestalozziano" (Bembo, 1913, p. 5). Como ya hemos dicho, Bembo se considera un genuino representante del método de Pestalozzi. Así fundamentaba y perseguía los principios de una educación popular, intuitiva, cultural, moral, espiritual, armónica, positivista, gradual y progresiva, familiar, utilitaria, al aire libre y humanitaria de la libertad en desarrollando de pleno de todas las facultades. Pero, además, Bembo se consideraba continuador de la obra de Francisco Amorós, Pablo Montesinos, Julián López Catalán y Andrés Manjón. Para él, el método de Pestalozzi (el neo-pestalozzismo o la paidología de Claparède) era el mejor para atender la educación de los anormales.

Bembo se propuso rehabilitar el desacreditado método gimnástico de Amorós. Así presentó en un artículo (dividido en dos partes) una síntesis del método amorosiano, diciendo que en su base se encontraba la "gimnástica pestalozziana" (Bembo, 1912a, 1912b). En este documento se destacan los resultados generales que perseguía dicha educación: "la salud, el prolongamiento de la vida, la mejora de la especie humana, el aumento de fuerza y riqueza individual y pública" (Bembo, 1912a, p. 74). Aparte, trataba sobre las capacidades físicas: fuerza, firmeza, resistencia, velocidad, agilidad y destreza. Se ocupaba, además, de la educación físico-moral o del desarrollo de las facultades de Regularidad, Perseverancia, Celo, Gracia, Valor y Energía; pero también, de la moral en sí misma, para el desarrollo de las facultades de Previsión, Prudencia, Templanza, Bondad, Generosidad y Amor del bien.

Al revitalizar el método de Amorós, Bembo se anteponía al disciplinado y militarizado método gimnástico sueco, que en España empezaba a estar de moda bajo la protección de 
las instancias militares y médicas, y por algunos de los más acreditados profesores de educación física. El método de Amorós se presentaba como natural, creativo e incluso cooperativo. Por lo que el método natural, presentado por el teniente de Marina George Hébert (1875-1957), ese mismo año en Francia, no era otra cosa que una evolución del método de Amorós. En Francia, al finalizar la Primera Guerra Mundial, el método de Hébert fue reconocido como el más idóneo para adiestrar físicamente al ejército, con lo cual, el pueblo galo, que tanto había apostado por el método sueco, volvía a recuperar un método de inspiración propia.

Bembo se mostraba preocupado por las pésimas condiciones de vida de la clase obrera y los ambientes malsanos que marcaban la degeneración de la juventud (alcoholismo, delincuencia, prostitución, explotación de la infancia...):

...grupos de hombres, en su mayoría adolescentes, de talleres y fábricas, se estacionan
delante de una ellas, y por un precio módico hacen el coito bucal, masturban y el coito
normal, a la vista de todos, que les excitan con palabras soeces. Estas prostitutas,
llamadas, en términos populares pajilleras, son desecho del ejército del vicio; muchas
de ellas obreras, otras ex artistas de cafés-concerts, feas y ajadas... (Bembo, 1912c,
p. 231)

En febrero de 1913, Bembo regresó a Sabadell y se estrenó como primer director de la Institución Integral Armónica (1912), centro educativo que seguía la línea marcada, ya anteriormente, por la Institución Libre de Enseñanza (ILE) (Delgado, 1978, 1979). Este proyecto contaba con el apoyo de la Federación Obrera de Sabadell y un amplio grupo de entidades culturales. La escuela se ubicó en la c/ Mediodía, 47-48, y recibió la colaboración del Instituto de Educación Integral y Armónica de Barcelona, que contaba con singulares educadores como Federico Climent, Antoni Sabater o Ramon Maynadé (Alsina, 1982; Carreras, 1931; Masjuan, 2006).

En el Instituto de Educación Integral y Armónica (1912, p. 41), el teosófico Federico Climent y sus colaboradores (entre ellos Bembo), señalaban para la segunda etapa escolar que los "ejercicios físicos pueden ya disciplinarse parcialmente por medio de la gimnasia, aunque sin prescindir de los juegos de movimiento, cuya acertada regularidad deparará ocasión de apartar del niño los juegos callejeros y moderar su natural turbulencia". Para la tercera infancia, buscaban medios de educación física para equilibrar y robustecer los músculos "a fin de contrarrestar la excitación nerviosa" (Instituto de Educación Integral y Armónica, 1912, p. 48).

Bembo se impregnó de los ensayos racionalistas de la época, a destacar el de Francesc Ferrer Guardia y Albán Rosell (Torrebadella, 2016), y de la influencia de la feminista sueca Ellen Key (1849-1926), autora de "El Siglo de los niños" (1906), obra que también cautivó a los círculos pedagógicos críticos de la época (Solà, 2011). Además, en cuanto a la educación física, Bembo coincidía con Key y escogía la práctica de la gimnástica natural, el juego libre y los deportes, pero siempre procurando el contacto con la naturaleza.

De las conferencias que Bembo realizó en Sabadell descubrimos las líneas educativas de su proyecto. Se presentó a la sociedad como un reformador de la enseñanza tradicional y hablaba sobre "el error y la mentira en la escuela" (Alsina, 1982, p. 5). Bembo concedió importancia a la enseñanza de la lengua materna, suprimía el castigo por la reflexión y el diálogo, priorizó el conocimiento industrial y artesanal, otorgó mucha importancia a la escuela al aire libre, al cultivo de la tierra, al excursionismo, a los intercambios escolares -utilizando para ello el deporte- (Noticias, 1913), introducía la enseñanza del esperanto 
y otorgaba gran importancia a la educación estética, con lo que promovió grupos de teatro y orfeones infantiles. En cuanto a la educación de la mujer, se inclinó por una visión tradicional, pero sin la sujeción del sentido religioso dominante.

Bembo era un filántropo idealista y deseaba hacer de Sabadell una "Pequeña Europa”, un ensayo cultural de raíz popular que fuese modélico con la complicidad del pujante asociacionismo obrero. En pocos meses, lideró un ambicioso plan con infinidad de conferencias, clases al aire libre, asociaciones culturales, equipos de fútbol, un grupo de teatro y un orfeón infantil, además de la "Casa de muñecas", en donde se pretendía sensibilizar a las niñas hacia la cultura maternal. Pero como ya hemos dicho, este sueño utópico no conectó con el interés de las clases dirigentes de esta significativa población industrial (Alsina, 1982, Masjuan, 2006).

\subsection{El fútbol en la obra de Max Bembo}

A principios del siglo Xx, en Barcelona, el fútbol arrebató el protagonismo a muchos de los juegos populares más en boga. Uno de estos juegos, quizás el más popular en la escuela y fuera de ella, era el marro o riscat. Cuando aparecía un balón los niños se olvidaban del marro (Brasó y Torrebadella, 2015). La rápida expansión del fútbol en Barcelona desencadenó una eclosión del asociacionismo futbolístico. Muchos de estos equipos eran escolares; jóvenes de institutos y universitarios que muy pronto fueron seguidos por equipos infantiles. Como cita Torrebadella (2012b), al llegar a 1903 en esta ciudad ya se habían creado medio centenar de equipos. En las calles el fútbol era el juego de moda:

La afición ha cundido de tal modo, que todo el mundo juega ya á futbol... jes tan fácil cosa esa de lanzarse la pelota! Nuestra juventud, la que puede, acapara todos los balones de El Siglo, y la que no, juega con piedras, con cajas de cartón, con lo que sea factible de empujarse con los pies é introducirse en el goal. Preferible es eso que jugar al toro ó jugar con fuego, disfrazándose en estos días de mujer. (Intimidades, 1903, p. 134)

En estos años el fútbol se presentó como un poderoso elemento de educación física, de regeneración de la juventud y social (Barba, 1912; Elias, 1914; Gibert, 1917). El fútbol se señalaba como un deporte ideal para el ejército (Barba, 1912), pero, además, fue utilizado como instrumento portador de valores civilizadores, idealizados también en el discurso del Noucentisme (D’Ors, 1988).

En ocasiones, los equipos más importantes colaboraron para recaudar fondos en apoyo a diferentes iniciativas de beneficencia. Muchos partidos de fútbol y otros eventos deportivos ayudaron a la OMB. En la ciudad, el deporte también se revestía de humanidad y de solidaridad, y se presentaba así, de acción moralizadora, civilizada y noble.

Torneo benéfico. Hoy, a las tres de la tarde, tendrá lugar en el campo del «R. C. D. Español» un torneo a beneficio de las Escuelas Max-Bembo, habiendo se inscripto los primeros equipos de la Primera Liga adheridos a la F. C. C. F. «Español», «España», «Polo», «Casual»y «Numancia». Al equipó vencedor se le adjudicará. Una Copa de plata, donada por el Alcalde de Sabadell y las medallas de plata, y para los otros clasificados hay cuatro objetos de arte donados por importantes casas. (El Mundo Deportivo, 22 de mayo de 1913, p. 4)

Bembo también incorporó el fútbol y estimuló la constitución de equipos. En este sentido, pude decirse que utilizaba el deporte como un medio para la educación física y moral de los jóvenes, del mismo modo que ya lo estaba desplegando la ILE (López Serra, 
1998; Torrebadella, 2012b). En 1913 desabrimos que "los alumnos de la Institución Max Bembo han constituido una sociedad de lawn-tennis a la cual prestará su apoyo el Helénico Foot-ball Club, constituido recientemente e integrado asimismo por los alumnos de la altruista citada institución” (Nueva Entidad, 1913, p. 3). Se da el caso que la Junta Directiva de la nueva entidad estaba compuesta íntegramente por el sexo femenino, bajo la presidencia honoraria de Carmen Rodríguez Méndez, y la presidenta ejecutiva de Ramona Estellé.

En la escuela de Sabadell, Bembo creó el equipo de fútbol infantil "Petits Crusaders", que disputó algunos partidos contra equipos de Barcelona, estableciendo, de paso, las relaciones de intercambio entre los escolares y estimulando el fomento de la amistad. También utilizó el campo del Centre d'Esports para hacer algunos entrenamientos (Alsina, 1982). También en Sabadell se disputaron algunos partidos con el fin de recaudar dinero para la escuela (Alsina, 1982). Puede decirse que Bembo fue uno de los primeros promotores de una obra benéfica, que utilizó el deporte para concienciar a la población y recaudar fondos. A beneficio de la OMB, en julio de 1913, se realizó un "Festival Deportivo", que consistió en la realización de varios partidos de fútbol, uno de los cuales entre los infantiles del Centre d'Esports y los "Petits Crusaders", después se disputaron unas pruebas atléticas. En este Festival colaboraron el Centre d'Esports, atletas de Barcelona, “El Mundo Deportivo”, el Ayuntamiento y el empresario local Josep Germà (Atletismo. Festival Deportivo en Sabadell, 1913).

Con el título de «Petits Crusaders», se ha consumido en Sabadell con los elementos
infantiles de las escuelas que dirige el profesor Max Bembo, un Club de foot-ball,
cuya presidencia honoraria ha aceptado el excelente jugador sabadellés, Amadeo
Aragay. Los «Petits Crusaders» pedirán el ingreso en la F. C. C. F. El día 8 de
abril vendrá á Barcelona á celebrar un mach con el Helénico. Club infantil de la
institución de Max Bembo. La junta ha quedado constituida en esta formada
presidente honorario, don Amadeo Aragay; presidente, don Juan Romeu,
vicepresidente, don Enrique Mora; secretario, don Enrique Serra; tesorero, don
Víctor Donénech, y vocal, don Esteban Coromimas. Con sitio de entrenamiento han
ocupado el campo del Centre de Sports, de Sabadell, y el uniforme consiste en
camiseta blanca y pantalón marrón. (Foot-ball, 1913, p. 13)

En 1914 localizamos varios campeonatos de Fútbol en beneficio de la OMB, uno fue la “Copa Amorós” (Correo de los Niños, 1914; El Mundo Deportivo, 1914). Bembo también se involucró con todo lo concerniente al fútbol en edad escolar y amateur. En la revista Foot-ball propuso establecer una "Unión de clubs de Foot-ball no federados", para proteger la oleada de clubes humildes (Bembo, 1918a). Parece ser que también fue el promotor de otras entidades, sobre una de ellas mencionaba: "como un secreto a voces, lo que yo he sufrido y padecido por arraigar el Centre de Sports de Santa Coloma de Gramanet, y yo no sé si me lo pagaran con creces los esfuerzos hechos” (Bembo, 1918b, p. 4$)$.

Bembo pedía así, la democratización del fútbol, proponiendo una alternativa para encauzar su práctica hacia las esferas de la clase obrera. Con lo cual, también surgía la necesidad de fomentar y apoyar las iniciativas de los clubes de las barriadas obreras, como solución a la educación social y a la concordia interna de la ciudad.

\subsection{Fútbol y educación social a princípios de siglo $\mathrm{XX}$}

El fútbol de élite representa las legitimidades de un sistema de estructuras sociales estructurizantes que producen y reproducen la normalización de códigos disciplinantes 
como el respeto a la autoridad, la conciencia jerárquica, el control de la práctica, la obediencia, la colectividad, la ética de trabajo y el ganar (Cushion y Jones, 2014). En la educación física, la incorporación del fútbol es algo más que un simple juego. Se presenta todavía como el subterfugio pedagógico para mejorar el rendimiento escolar de los chicos (Skelton, 2000). La poderosa carga histórica y cultural del deporte, y en especial la del fútbol, como valor hegemónico de la masculinidad y de la heterosexualidad (Barbero, 2003), es un elemento que pone freno a la educación física hacia un posible cambio de paradigma (Soler, 2006).

Desde finales del siglo XIX, la Asociación Catalana de Gimnástica intentó concienciar al Ayuntamiento de Barcelona para que construyese campos de juego para la población infantil y juvenil (Torrebadella, 2015a, b). En este asunto, el fútbol era sin duda el principal perjudicado y, como citaba Josep Elias (1903), a principios del siglo veinte en muchas de los espacios públicos de Barcelona se improvisaban partidos de este juego.

En 1912 Hermenegildo Giner de los Ríos (1847-1923), principal impulsor de la política educativa y cultural de Barcelona por el Partido Radical de Lerroux, pedía establecer campos de juego cercanos a las escuelas, que consideraba indispensables para "convertir la gimnasia artificial en la natural de los deportes variados" (Giner, 1979, p. 60).

El fútbol se había puesto de moda entre todos los jóvenes de Barcelona, por lo que era ineludible el no contemplar o dirigir sus potenciales educativos. Así lo sugería Federico Climent (1906), al considerar que era un deporte eminentemente educativo, puesto que disciplinaba el espíritu a la obediencia de las normas, sin que se quebrantase la autonomía personal. Ante esta predilección, Climent tenía el fútbol como un medio de formación social y nacional. Al respecto citaba que "conviene someter al niño, durante las horas de clase, a ejercicios colectivos de carácter militar que le acostumbren a la obediencia y disciplina, y le preparen a la obligación que de servir a su patria tiene todo ciudadano" (Climent, 1906, p. 60). El fútbol proporcionaba el estímulo suficiente para reunir, en un punto en concreto conocido, a educandos (niños y adolescentes), por lo que se convertía en un juego espontáneo, en el que éstos se podían expresar con entera libertad, creyendo que nadie les estaba observando (vigilando).

La disciplina también era para Hans Gamper (1911) y Graham (1913) la principal característica del fútbol. Se trataba de una disciplina de obediencia al capitán y de sacrificio hacia un provecho colectivo, en la que también se aprendía el dominio de si mismo (Self-government). Alejandro Barba (1912, p. 6) veía en el fútbol un substancial recurso para la existencia de todas las clases sociales, un elemento "para formar al ciudadano que ha de desempeñar un brillante papel en la vida social y política de la nación”:

En las grandes capitales, la juventud debe buscar en los incidentes de esta lucha la pérdida de fuerzas que sufre la vida enervante del escritorio, y de los placeres deprimentes que agotan las energías, atrofian iniciativas y crean una generación anémica impropia para el combate de la existencia. (Barba, 1912, p. 127-126)

Además, Barba (1912) apreciaba en este deporte un poderoso agente cuyo carácter viril, atlético y rudo encajaba perfectamente con la instrucción militar y patriótica a la que todos los jóvenes en el futuro deberían prestar servicio (Torrebadella, 2017).

Para Graham (1913, p. 13-14), el fútbol era un "elemento de educación física y moral que substrae de la vida enervante de los placeres mundanos y a los vicios y malicia de la sociedad moderna”. En Barcelona, esta idea que era ampliamente compartida en las 
esferas burguesas y así se manifestaba en las declaraciones de los promotores de este deporte (Elias, 1914; Hans, 1911):

El Foot-Ball como elemento pedagógico y de cultura física, es sin disputa alguna el mejor y más completo de los deportes. En su práctica, pónense en juego, sin esfuerzo aparente y sin la enervante monotonía rítmica de la gimnasia, todos, absolutamente todos los músculos del cuerpo. Los movimientos adquieren, instintivamente, vivacidad y rapidez, la vista se aguza y la inteligencia, aun cuando muchos crean lo contrario, está sometida a un ejercicio activísimo, pues no en balde, se ha llamado al Foot-Ball el ajedrez de los deportes.

Los jóvenes y aun los niños, curtidos por el sol y atesados por el viento, practican jugando al aire libre la mejor y más eficaz gimnasia. Los cuerpos antes encorvados, de pechos hundidos, de estrechas espaldas, de débiles miembros y poco resistentes pulmones, adquieren paulatinamente y sin fatiga, vigor, y armonía estética, convirtiendo en hombre robusto, apto para las luchas de la vida, al adolescente enclenque, recién salido del colegio, donde practicó una gimnasia la mayor parte de las veces, divorciada del todo, con la higiene y el sentido común. (Hans, 1911, p. I)

El reconocido profesor de educación física Marcelo Sanz Romo -presidente de la Asociación de Profesoras y Profesores de Oficiales de Educación Física-, aunque se mostró contrario al valor educativo del fútbol (Torrebadella, 2012a), apreciaba en este deporte su potencial disciplinario y socializador como "escuela de solidaridad":

Los equipos están muy disciplinados, y son muchos individuos bajo la autoridad de uno solo; son unos obreros que ejecutan en conjunto un trabajo especial; más todavía: el equipo es un organismo moral que nace, se desenvuelve, vive, prospera y triunfa, por la acción de todos, y no puede subsistir sin la disciplina; necesita un jefe verdadero y único, cuya autoridad no solo sea externa, sino que es interna, y forma parte del ser, constituye una unidad moral, por lo que es precisamente el aspecto más importante de la organización de un equipo, el aspecto interno es la acción moral que penetra hasta lo intimo de los sentimientos, cautiva el corazón, subordina la voluntad y domina los instintos egoístas.

Esta es la virtud del juego, la gran escuela de solidaridad: este gran secreto es el que debemos aprovechar para desenvolver el carácter; el jugador que comete una torpeza o que hace una mala acción en el juego, lleva el castigo en el sentimiento de pena que produce su falta, y en lo sucesivo procurara unir su esfuerzo a los otros para que converja con todos hacia un fin común o una idea fija, la de la victoria. (Sanz, 1913, p. 115-116)

Por estas razones y ante la palmaria homosexualidad de la vida barcelonesa que describía Bembo (1912a), un contra-modelo que disputaba la virilidad (Uría, 2008), el fútbol se percibía repleto de ingredientes socializadores, que substraían a "la juventud de la creciente vorágine de las pasiones, a que predispone la vida agitada y agobiante de las grandes urbes modernas" (Gamper, 1914, p. 13).

Puede decirse que el fútbol se presentaba como un idealizado antídoto para neutralizar la entonces llamada afeminación de los jóvenes, que era lo mismo que utilizarlo como dispositivo regeneracionista y regenerador, es decir, hacia el encauzamiento de la masculinidad hispana (Vázquez García y Cleminson, 2011):

El Foot-ball es la preparación de la juventud para la lucha por la vida: es la regeneración de la sociedad. La divisa del juego "uno para todos y todos para uno", es la escuela de obediencia dentro de la iniciativa; un buen jugador es la abstracción de su personalidad egoísta en bien a la personalidad colectiva del equipo. Desde el punto de vista de la estrategia del combate y de la formación del hombre apto para el servicio militar, el Foot-ball permite revelarse los caracteres y afianzar el temperamento del jefe; el juego es una lucha con una táctica, sus combinaciones, su estrategia un juego de ataque y defensa, de sorpresas con sus apoyos y reservas. El 
deporte es una escuela de buenas costumbres, teniendo justa aplicación el consejo de Michelet: Para ser fuerte puro; el jugador que tenga pundonor, acumulará el máximum de energías mediante la vida metódica y lo más higiénica posible; se acostará temprano, y al levantarse practicará entrenamiento, dejará las bebidas alcohólicas y los hábitos de la temperancia; los baños y las duchas serán habituales. (Riera, 1918, p. 3)

\section{Conclusiones}

Max Bembo fue un educador urbano intelectual y comprometido que actuó siempre en un sentido crítico y de justicia social. La praxis y su pensamiento activista se entroncaba en la línea de influencia masónica (como su tío Rodríguez Méndez), teosófica (como Federico Climent) y cercana al librepensamiento (de Ferrer Guardia). Bembo aportó una posición crítica y postmoderna. Su denuncia social se trasladaba a la acción práctica y utilizó los dispositivos regeneradores de moda, como el teatro, el cine, y también la gimnástica y el deporte. Sin embargo, estos dos últimos los utilizó de forma muy distinta. Bembo no adoptaba la gimnasia disciplinada y uniformada del sistema sueco, sino que recuperó la gimnasia natural de Francisco Amorós. En cuanto al fútbol, fue mucho más que una práctica recreativa y de moda, se presentaba por su función higienizadora, socializadora y el espíritu combativo de lucha por la vida. Bembo descubrió que, a través del fútbol, la clase obrera podía aspirar a cotas de progreso social, sobre todo, alejándola de los espacios de corrupción (alcohol, delincuencia, prostitución...).

No cabe duda que con el fútbol nació un importantísimo germen del asociacionismo infantil moderno. Esto sucedía en un momento en el que también se encauzaban otras asociaciones vinculadas al tiempo libre infantil, pero con un sello profundamente ideológico (Exploradores de España, Requetés infantiles, Pomells de la Juventut...). En cambio, la mayoría de las asociaciones deportivas tenían un carácter autónomo y se presentaban despolitizadas. En el caso del Foot-ball Asociación, el adjetivo ya lo decía todo. Sí, hacía falta una asociación, es decir, una agrupación de personas dispuestas a compartir un juego que consiste en unirse y colaborar para ganar a un equipo adversario.

Sostener que el fútbol se desarrolló en España a través de las iniciativas pedagógicas escolares, no es del todo cierto. También se desarrolló por la espontánea iniciativa de los juegos de la calle (fuera de la escuela), de la verdadera necesidad recreativa del propio juego, es decir, de la necesidad de compartir una iniciativa re-creadora libre entre compañeros. Por lo tanto, inmediatamente, también se fraguó como extensión escolar (extraescolar y postescolar). De aquí que rápidamente, los educadores se percatasen del potencial que tenía el juego para el control de la infancia y la adolescencia. Sencillamente se tenía que agrupar a una multitud de niños en un mismo espacio, con un balón, para practicar juntos una misma actividad, el fútbol. El paso siguiente se presentaba fácil, había que buscar un capitán o un presidente (un líder), una figura que fuese respetada por todos para liderar la creación de una asociación deportiva, una empresa compartida, un proyecto en común para la comunidad, cuyos valores se sostenían por una sociedad que se presentaba disciplinada, civilizada y moderna.

Entre las principales aportaciones de Max Bembo a la educación social, hemos querido destacar precisamente el potencial educativo y socializador que vio en el deporte, en este caso el fútbol. En aquella época, el fútbol envolvía un mundo de ascenso para el joven 
desamparado. A través del deporte, eso sí, como premio a la buena conducta, el joven entraba en un nuevo círculo esperanzador y protector de relaciones sociales. Así, el equipo y los compañeros se constituían en una nueva familia, surgían amistades forjadas en la lógica interna de los valores competitivos del fútbol: cooperación, lucha, esfuerzo, superación, etc., valores que encarnaban el espíritu de aquellos jóvenes que se enfrentaban, sin más, a las vicisitudes de la vida, enarbolando el mito de la regeneración.

En este sentido, el fútbol se articuló también como dispositivo que coadyuvaba al control social de la clase obrera, con lo cual se apropió de los atributos de regeneración, civilización, modernización y progreso. No obstante, en el caso particular de Bembo, subyacía, además, una voluntad honesta, una idea filantrópica sobre el problema social y de auxilio a la infancia y la juventud más necesitada; se trataba de una moral sincera, que superaba la moral burguesa consabida.

Finalmente, con este artículo nos hemos propuesto superar el espacio residual que tiene aún hoy la Historia de la Educación Social (Hernández Díaz, 2008), y avanzar en la construcción de una disciplina que sostiene amplias conexiones sociales (políticas, culturales, económicas...). Si, por un lado, nos enfrentamos a la poca información documental de fuentes primarias, por el otro, también encontramos la falta de estudios relacionados con la historia de la educación social en España. En este asunto, hemos resaltado aquellas realizaciones olvidadas, por la historia de la educación física y el deporte, que también atendían a una dimensión que iba más allá de las medallas deportivas. Sin embargo, reconocemos que tan sólo hemos iniciado la tarea de presentar la obra filantrópica de Max Bembo y el perfil humano de un hombre, del cual aún queda mucho por destacar.

\section{Referencias}

Agrupación Pestalozziana. (1913). A Enrique Pestalozzi (1746-1827). Barcelona: J. Domenech.

Alsina, J. (1982). L’assaig pedagògic de Max Bembo a Sabadell. Sabadell: Fundació Bosch i Cardellach.

Álvarez-Uría, F. (1987). Los niños “anormales”. Constitución del campo de la infancia deficiente y delincuente. En C. Lerena (Ed.), Educación y sociología en España. Selección de textos (pp. 6278). Madrid: Akal.

Atletismo. Festival Deportivo en Sabadell. (24 de julio de 1913). El Mundo Deportivo, pp. 4-5.

Ayuntamiento de Barcelona. (1909). Anuario estadístico de la ciudad de Barcelona, 1907. Barcelona: Herich.

Ayuntamiento de Barcelona. (1914). Anuario estadístico de la ciudad de Barcelona, 1912. Barcelona: Herich.

Ballester, R. y Balaguer, E. (1995). La infancia como valor y como problema en las luchas sanitarias de principios de siglo en España. Dynamis, 15, 177-192.

Barba, A. (1912). Football, basse ball y lawn tennis. Barcelona: Ed. Sucesores de M. Soler.

Barbero, J. I. (2003). La educación física y el deporte como dispositivos normalizadores de la heterosexualidad. En O. Guasch y O. Viñuales (Eds.), Sexualidades. Diversidad y control social (pp. 355-377). Barcelona: Ediciones Bellaterra. 
Barona, J. L. (2007). ¿Por qué mueren los niños? El debate ideológico sobre la salud infantil en la sociedad española (1904-1939). En R. Campos, L. Montiel y R. Huertas (Coords.), Medicina, ideología e historia en España (siglos XVI-XXI) (pp. 287-299). Madrid: CSIC.

Bembo, M. (13 de enero de 1907a). A favor de los desamparados. En defensa de un proyecto. La Publicidad, p. 2.

Bembo, M. (16 de marzo de 1907b). A favor de los desamparados. La Vanguardia, p. 4.

Bembo, M. (1907c). Miseria y filantropía a favor de los desamparados. Barcelona: A. López.

Bembo, M. (11 de mayo de 1909). Notas locales. La Vanguardia, p. 3.

Bembo, M. (12 de mayo de 1910). Notas locales. La Vanguardia, p. 3.

Bembo, M. (1912a). Historia de la enseñanza: Los niños del Coronel Amorós. Archivos de Pedagogía y Ciencias Afines, 11(31), 73-89.

Bembo, M. (1912b). Conclusión: Historia de la enseñanza: Los niños del Coronel Amorós. Archivos de Pedagogía y Ciencias Afines, 11(32), 227-269.

Bembo, M. (1912c). La mala vida en Barcelona. Barcelona: Maucci.

Bembo, M. (1913). Doctrina pestalozziana. Introducción a una historia de la doctrina pestalozziana y los orígenes del conocimiento científico en pedagogía. Barcelona: Tip. La Académica.

Bembo, M. (1916a). ¡Nuestros niños se mueren de hambre! La Ciudad de los Niños, 3, 11-12.

Bembo, M. (1916b). La infancia abandonada. La trata de blancas y la prostitución de menores de edad en Barcelona. La Ciudad de los Niños, 3, 1-6.

Bembo, M. (1916c). Organización de las obras de Max-Bembo. La Ciudad de los Niños, 5, 9-20.

Bembo, M. (15 de agosto de 1918a). Carta abierta ¿Fuera posible la unión?. Foot-ball, p. 3.

Bembo, M. (29 de agosto de 1918b). Mas sobre la proyectada. Unión de clubs de foot-ball no federados. Foot-ball, pp. 4-5.

Brasó, J. y Torrebadella, X. (2015). El marro, un juego tradicional y popular en la educación física española (1807-1936). Revista Complutense de Educación, 26(3), 697-719.

Campos, R. (1998). La teoría de la degeneración y la medicina social en España en el cambio de siglo. Llull, 21, 333-356.

Cañellas, C. y Toran, R. (1982). Política escolar de l'ajuntament de Barcelona, 1916-1936. Barcelona: Barcanova.

Carreño, M. (2009). Reflexiones sobre el por qué y el para qué de la educación de infancia anormal según el discurso médico-pedagógico español de los inicios del siglo XX. Revista Educación y Pedagogía, $17(42)$, 31-44.

Carreras, M. (1931). El problema de l'ensenyança primària a Sabadell. Plantejament $i$ antecedents. Sabadell: Edicions de la Comissió de Cultura de l'Ajuntament de Sabadell.

Climent, F. (1906). Educación de los niños. Barcelona: Sucesores de Manuel Soler.

Correo de los Niños. (13 de mayo de 1914). Deportivas. Correo de los Niños, p. 14.

Cushion, C. J. y Jones, R. L. (2014). A Bourdieusian analysis of cultural reproduction: Socialisation and the 'hidden curriculum' in professional football. Sport, Education and Society, 19(3), 276-298. https://doi.org/10.1080/13573322.2012.666966

D’Ors, E. (1988). L'home que treballa i juga. Vic: Eumo.

De la Riva, A. (1916). Nuestros festivales. Los reyes magos. La Ciudad de los Niños, 5, 23-26. 
Del Cura, M. y Huertas, R. (2009). Higiene mental y educación terapéutica: La pedagogía ortofrénica en la España del primer tercio del siglo XX. Historia de la Educación, 28, 80107.

Delgado, B. (1978). La institución libre de enseñanza de Sabadell. Revista Española de Pedagogía, 36(141), 137-153.

Delgado, B. (1979). La institución libre de enseñanza de Sabadell. Sabadell: Fundació Bosch i Cardellach.

El Mundo Deportivo (14 de mayo de 1914). Concurso “Copa Amorós”. El Mundo Deportivo, p. 5.

Elias, J. (20 de septiembre de 1903). Sports. La Ilustració Catalana, p. 259.

Elias, J. (1914). Football asociación. Barcelona: Imp. R. Tobeña.

Emmanuel, J. A. (1931a). Francisco Ferrer el mártir ;Obrera anarquízate! El sindicalismo y la acción anárquica en los sindicatos. Barcelona: BAI.

Emmanuel, J. A. (1931b). La anarquía explicada a las mujeres. Barcelona: BAI.

Emmanuel, J. A. (1931c). La anarquía explicada a los niños. Barcelona: BAI.

Emmanuel, J. A. (1931d). Lo que debe saber todo anarquista. A la confederación regional del trabajo de Andalucía y Extremadura. Barcelona: BAI.

Emmanuel, J. A. (1931e). Organización anárquica del mundo. A las federaciones locales de los sindicatos de España. Barcelona: BAI.

Emmanuel, J. A. (20 de diciembre de 1931f). Las escuelas racionalistas y la educación del proletariado. Solidaridad Obrera, p. 2.

Esteruelas, A., García, J. y Vilafranca, I. (2015). L'escola del Bosc cent anys després. Allà on Rosa Sensat va sistematitzar la seva pedagogogia. Temps d'Educació, 49, 111-133.

Ferrer, T., Somoza, M. y Badanelli, A. M. (2014). Historia de la educación social. Madrid: UNED.

Foot-ball. (1 de abril de 1913). Crónica telegráfica de provincias. La Vanguardia, p. 13.

Gamper, J. (1914). Prólogo. En J. Eliess (Coord.), Football asociación (pp. 9-18). Barcelona: R. Tobeña.

Gibert, S. (1917). ¿Quiere V.jugar al foot-ball? Barcelona: Ediciones Bauza.

Giner, H. (1979). Preceptos pedagógicos para el profesorado de las escuelas libres, neutrales o laicas de niños y niñas. Barcelona: José J. de Olañeta.

Givanel, J. (1931). Bibliografia catalana. Barcelona: Givanel.

González-Agàpito, J. (1992). L'escola nova catalana, 1900-1939: Objectius, constants i problemática. Barcelona: Eumo.

Graham, G. (1913). Novismo tratado de foot-ball. Método práctico para jugar al foot-ball y apreciar la licitud y oportunidad de los jugadores. Barcelona: Ciencias y Letras.

Hans Gamper, H. (1 de agosto de 1911). La táctica en el foot-ball. Stadium, pp. 1-2

Hernández Díaz, J. M. (2008). La disciplina historia de la educación social hoy en España. Cuadernos de Historia de la Educación, 4, 11-22.

Huertas, R. (1998). Niños degenerados: Medicina mental y “regeneracionismo” en la España del cambio de siglo. Dynamis, 18, 157-179.

Huertas, R. (2004). El niño golfo: Infancia y delincuencia en el pensamiento médico social del cambio de siglo. En E. Perdiguero (Comp.), Salvad al niño. Estudios sobre la protección de la 
infancia en la Europa mediterránea a comienzos del siglo XX (pp. 301-331). Valencia: Universidad de Valencia.

Huertas, R. (2009). Los niños de la mala vida: La patología del golfo en la España de entresiglos. Journal of Spanish Cultural Studies, $10(4), \quad 423-440$. https://doi.org/10.1080/14636200903400207

Hutchinson, J. (2008). Sport, education and philanthropy in nineteenth-century Edinburgh: The emergence of modern forms of football. Sport in History, 28(4), 547-565. https://doi.org/10.1080/17460260802580610

Instituto de Educación Integral y Armónica. (1912). Orientaciones pedagógicas. Barcelona: Domingo Clarasó.

Intimidades. (1 de marzo de 1903). Orígenes, nacimiento y consolidación. Los deportes, p. 134.

Juderías, J. (1908). La protección de la infancia en el extranjero. Madrid: Imprenta de Eduardo Arias.

Key, E. (1906). El siglo de los niños. Barcelona: Herrich

La escuela del bosque. (8 de septiembre de 1911). La Vanguardia, p. 2.

La Obra de Max Bembo. (12 de enero de 1923). La Vanguardia, p. 5.

Le Goff, J. (1991). El orden de la memoria. El tiempo como imaginario. Barcelona: Paidós.

Le Goff, J. (2012). Pensar la historia. Modernidad, presente, progreso. Barcelona: Paidós.

López Serra, F. (1998). Historia de la educación física de 1876 a 1898. La institución libre de enseñanza. Madrid: Gymnos Editorial.

Martí, D. (1984). Per Catalunya i altres textos. Barcelona: La Magrana.

Masjuan, E. (2006). Medis obrers i innovació cultural a Sabadell (1900-1939): L'altra aventura de la ciutat industrial. Bellaterra: Universitat Autònoma de Barcelona.

Notas locales. (10 de enero de 1907). La Vanguardia, p. 2.

Noticias. (22 de marzo de 1913). La Publicidad, p. 5.

Nueva Entidad. (8 de abril de 1913). La Publicidad, p. 3.

Orfeonato Max Bembo. (16 de setiembre de 1920). La Vanguardia, p. 5.

Palau, A. (1935). Memorias de un librero catalán, 1867-1935. Barcelona: Llibreria Catalònia.

Pujadas, X. y Santacana, C. (1995). Esport, catalanisme i modernitat. La Mancomunitat de Catalunya i la incorporació de la cultura física en l'esfera pública catalana. Acàcia, 4, 101121.

Riera, C. (21 de febrero de 1918). De Divulgación. Foot-ball, pp. 3-4.

Rodríguez Pérez, J. F. (2009). La protección de la infancia en España. Ayer y hoy. En J. L. Hernández Huerta, L. Sánchez Blanco y I. Pérez Miranda (Coord.), Temas y perspectivas sobre educación. La infancia ayer y hoy (pp. 29-43). Salamanca: Anthena.

Ruano, R. (2013). Contra la ignorancia: Textos para una introducción a la pedagogía libertaria. Barcelona: El Viejo Topo.

Ruiz, C. y Palacio, I. (1999). Higienismo, educación ambiental y previsión escolar. Antecedentes y prácticas de la educación social en España (1900-1936). Valencia: Universidad de Valencia.

Sánchez-Valverde, C. (2009). La junta de protección de la infancia de Barcelona, 1908-1985. Aproximación y seguimiento histórico. Barcelona: Generalitat de Catalunya. 
Santolaria, F. (2009). La junta de protección de la infancia de Barcelona. La primera etapa (19081909). Educació i Història: Revista d'Història de l'Educació, 14, 75-91.

Santos, M. (2012). Una aproximación a la ley de mendicidad de 1903. Revista de la Inquisición, 16, 227-270.

Sanz, M. (1913). Ensayo de una higiene deportiva o de los deportes ante la higiene. Madrid: La Correspondencia Militar".

Skelton, C. (2000). A passion for football: Dominant masculinities and primary schooling. Sport, Education and Society, 5(1), 5-18. https://doi.org/10.1080/135733200114406

Solà, P. (2011). Ferrer Guardia pedagogo y hombre de acción: La mirada apasionada de Alban Rosell sobre el fundador de la escuela moderna. Barcelona: Clavell Cultura.

Solana, E. (1909). Curso completo de pedagogía. Madrid: El Magisterio Español.

Soler, S. (2006). Actitudes y relaciones de niñas y niños ante contenidos de la educación física de primaria estereotipados por el género: El caso del fútbol. Investigación en Ciencias del Deporte, 46, 116-146.

Torrebadella, X. (2012a). El deporte contra la educación física. Un siglo de discusión pedagógica y doctrinal en la educación contemporánea. Movimiento Humano, 4, 73-98.

Torrebadella, X. (2012b). Orígenes del fútbol en Barcelona (1892-1903). Revista Internacional de Ciencias del Deporte, 27, 80-102. https://doi.org/10.5232/ricyde2012.02706

Torrebadella, X. (2013). La aportación bibliográfica de Joan Bardina a la educación física moderna (1911-1939). Cabás, 9, 1-22.

Torrebadella, X. (2014). Regeneracionismo e impacto de la crisis de 1898 en la educación física y el deporte español. Arbor, 190(769), 1-23. https://doi.org/10.3989/arbor.2014.769n5012

Torrebadella, X. (2015a). Forjando los juegos olímpicos de Barcelona: La contribución de Narciso Masferrer y sala en la configuración del deporte nacional e internacional (1900-1910). Citius, Altius, Fortius, 8(1), 61-103.

Torrebadella, X. (2015b). Orígenes de la educación física en las escuelas públicas: El caso particular del Ayuntamiento de Barcelona durante el siglo XIX. Cabás, 13, 38-64.

Torrebadella, X. (2016). Francisco Ferrer Guardia, postmoderno avanzado y precursor de la educación física crítica. Análisis y reflexión para un giro didáctico. Educar, 52(1), 169-191. http://.doi.org/10.5565/rev/educar.756

Torrebadella, X. (2017). La militarización de la educación física escolar. Análisis de dos imágenes publicadas en la prensa de Barcelona de principios del siglo XX. Historia Social y de la Educación, 6(1), 78-108. https://doi.org/10.17583/hse.2017.2296

Torrebadella, X. y Brasó, J. (2017). Barcelona y el problema de la educación física en la primera enseñanza a principios del siglo XX. Las escuelas catalanas del distrito VI. Revista $\begin{array}{llll}\text { Brasileira de História } \quad \text { da } & \text { Educação, } & \text { 17(2), } & \text { 149-192. }\end{array}$ https://doi.org/10.4025/rbhe.v17n2.915

Torrebadella, X. y Nomdedeu, A. (2015). Los primeros libros de fútbol publicados en España (1900-1919). Revista General de Información y Documentación, 25(1), 113-139. https://doi.org/10.5209/rev_RGID.2015.v25.n1.48985

Uría, J. (2008). Imágenes de la masculinidad. El fútbol español en los años veinte. Ayer, 72, 121155. 
Varela, J. (1991). El cuerpo de la infancia. Elementos para una genealogía de la ortopedia pedagógica. En VVAA., Sociedad cultura y educación. Homenaje a la memoria de Carlos Lerena Alesón (pp. 229-248). Madrid: Universidad Complutense de Madrid.

Vázquez García, F. (1989). Estudios de teoría y metodología del saber histórico. Cádiz: Universidad de Cádiz.

Vázquez García, F. y Cleminson, R. (2011). Los invisibles: Una historia de la homosexualidad en España, 1850-1939. Granada: Comares.

Vilanou, C. y Planella, J. (2010). De la compassió a la ciutadania: Una història de l'educació social. Barcelona: UOC.

\section{Breve CV del autor}

\section{Xavier Torrebadella-Flix}

Licenciado en Educación Física por la Universidad de Barcelona y Doctor por la Universidad de Lérida. Profesor en el Instituto Centro de Alto Rendimiento Deportivo de Sant Cugat del Vallès (CAR) y en el Departamento de Didáctica de la Expresión Musical, Plástica y Corporal de la Universidad Autónoma de Barcelona. Miembro del Grupo de Investigación en Pensamiento Pedagógico y Social de la Universidad de Barcelona (GREPPS). Actualmente investiga en torno a la Historia Social y Documental de la Educación Física y el Deporte en España entre 1800 a 1939. Experto en las fuentes bibliográficas de la materia en el período de estudio. Dispone de varios libros en torno a la historia de la educación física y el deporte en España y decenas de artículos publicados en revistas nacionales e internacionales. ORCID ID: 0000-0002-1922-6785. Email: xtorreba@gmail.com 